Regular Article

ISSN 1226-8267

Journal of Forest Science

Vol. 28, No. 3, pp. 170-178, August, 2012

http://dx.doi.org/10.7747/JFS.2012.28.3.170

\title{
Modeling the Natural Occurrence of Selected Dipterocarp Genera in Sarawak, Borneo
}

\author{
Stephen $\mathrm{Teo}^{1,2, \star}$ and Mui-How Phua ${ }^{1}$ \\ ${ }^{1}$ School of International Tropical Forestry, Universiti Malaysia Sabah, 88400 Kota Kinabalu, Malaysia \\ ${ }^{2}$ Forest Department Sarawak, Universiti Malaysia Sabah, Level 5, Wisma Sumber Alam, 92660 Kuching, Sarawak, Malaysia
}

\begin{abstract}
Dipterocarps or Dipterocarpaceae is a commercially important timber producing and dominant keystone tree family in the rain forests of Borneo. Borneo's landscape is changing at an unprecedented rate in recent years which affects this important biodiversity. This paper attempts to model the natural occurrence (distribution including those areas with natural forests before being converted to other land uses as opposed to current distribution) of dipterocarp species in Sarawak which is important for forest biodiversity conservation and management. Local modeling method of Inverse Distance Weighting was compared with commonly used statistical method (Binary Logistic Regression) to build the best natural distribution models for three genera (12 species) of dipterocarps. Database of species occurrence data and pseudoabsence data were constructed and divided into two halves for model building and validation. For logistic regression modeling, climatic, topographical and edaphic parameters were used. Proxy variables were used to represent the parameters which were highly $(\mathrm{p}>0.75)$ correlated to avoid over-fitting. The results show that Inverse Distance Weighting produced the best and consistent prediction with an average accuracy of over $80 \%$. This study demonstrates that local interpolation method can be used for the modeling of natural distribution of dipterocarp species. The Inverse Distance Weighted was proven a better method and the possible reasons are discussed.
\end{abstract}

Key Words: Borneo, GIS, interpolation, Inverse Distance Weighted

\section{Introduction}

Borneo is one of the global mega diverse hotspots where biodiversity and endemism is high (Ashton 1995; Roos et al. 2004). However, deforestation is an inevitable part of development in the tropics including Borneo. It is estimated that the average deforestation rate for Borneo between 2002 and 2005 was $1.7 \%$ per annum with a higher rate of $2.2 \%$ per annum for peat swamp (Langner et al. 2007) which is about double the rate for the whole region of Southeast Asia as reported by Achard et al. (2002) and more than three times the global rate of tropical forest loss at $0.52 \%$.
Sarawak is no exception. Occupying the northwestern part of the tropical island of Borneo, the world's third largest and the second largest tropical island and located between latitudes $0^{\circ} 50^{\prime}$ and $5^{\circ} 1$ ' North and longitudes $109^{\circ}$ $36^{\prime}$ and $115^{\circ} 40^{\prime}$ East within area of approximately 124,449 sq $\mathrm{km}$ or $37.5 \%$ of Malaysia's total land mass, the tropical forests of Sarawak are converted to other land uses as well as logged to provide capital for development. Average annual deforestation rate calculated from land cover classification maps of 1990 and 2009 was $0.64 \%$ (Tsuyuki et al. 2011), which is much lower than that of Borneo. Bearing in mind that the deforestation rate for Sarawak was averaged

Received: June 13, 2012. Revised: July 6, 2012. Accepted: August 3, 2012 
over a long period of time and large scale oil palm plantation development was very recent, the rate is a conservative estimate. Given the situation on the current trends of deforestation and lack of proactive intervention measures, it is estimated that forest cover in Sarawak will decline further and thereby affecting biodiversity.

Several conservation plans, strategies and policies are, however, in place to cope with high deforestation rate such as the establishment of protected area system and reforestation. Sarawak is committed to gazette about $10 \%$ or about 1.2 million hectares of its total land area as Totally Protected Areas (national parks, nature reserves and wildlife sanctuaries) by 2020 under its Forest Ordinance and the Wildlife Ordinance. The existing Totally Protected Areas currently cover 534,747.5 hectares (source: Nature Conservation and Constitution Division, Forest Department Sarawak) or $4.46 \%$ of Sarawak's land area which is about slightly less than half of the target.

However, the quality of the protected area such as biodiversity is as important as the quantity (size) conserved. Dipterocarpaceae or dipterocarps is the dominant tree family of the tropical rain forests of Southeast Asia and a commercially important timber family as well. It has its centre of diversity in Borneo where at least 267 species are found. The northern part of Borneo harbors a higher wealth of biodiversity than the rest of Borneo. For instance, about 92\% of dipterocarps species in Borneo occur in Sarawak (Ashton 2004). Such keystone and dominant tree family ought to be conserved whereby there is a need to know where they are located in the landscape.

Species Occurrence or Distribution Model (SOM) can be defined as a model that relates species distribution data (occurrence or abundance at known locations) with information on the environmental and/or spatial characteristics of those locations whereby the model can be used to provide understanding and/or to predict the species' distribution across a landscape (Elith and Leathwick 2009). Species distribution modeling is significantly important for biodiversity conservation because it can determine areas that have high potential of occupancy by certain species (Nazeri et al. 2010). By conserving these areas that could be part of endangered species habitat, conservation strategies would be more effective.

The use of GIS with inventory data has been in- strumental in plant species distribution modeling (e.g. Raes et al. 2009; Jantakat et al. 2010). Raes et al. (2009) combined abundance data of angiosperm families (including Dipterocarps) in species distribution modeling using multiple linear regression. In a compilation of Peninsular Malaysian dipterocarps for plant red list, distribution map of dipterocarp for Sabah and Sarawak species that occur in Peninsular Malaysia were also included (Chua et al. 2010). The distribution map shows species occurrence polygons that are created by following the herbarium points, similar to the minimum convex polygon method. GIS-based modelling of dipterocarps distribution has been limited to only dry dipterocarp forest of Thailand (Jantakat et al. 2010). Distribution of ten tree species including five dipterocarp species was predicted using environmental variables in the dry dipterocarp forest in northern Thailand. The lack of such modeling study on dipterocarps could be due to unavailability of field data, which is very costly to collect. We, therefore, examine GIS-based approaches using the extensive herbarium database coupling with GIS data for modeling the distribution of dipterocarps in Sarawak. We compare the use of global and local modeling methods for modeling species of selected genera of dipterocarps in Sarawak.

\section{Materials and Methods}

All species of three genera of dipterocarps (Anisoptera, Dipterocarpus and Upuna) recorded from Sarawak were used in the study. The three genera were selected as members found in different habitats and included both endemics and non endemics. Upuna is a monotypic genus endemic to Borneo.

Dipterocarp species occurrence data for all 12 species of the three genera were digitized from the Sarawak Forest Herbarium's collection. The herbarium has an extensive collection of Bornean dipterocarp specimens including most of the type specimens. These data were complimented with pseudoabsence data obtained from botanical literatures as well as local and field knowledge for all the dipterocarps. Comprehensive ecological information accounts for all dipterocarps in Borneo are found in the Tree Flora of Sabah and Sarawak (Ashton 2004). The occurrence data were divided into two halves: one half to construct the model and 
Table 1. Number of data for model building and verification

\begin{tabular}{lrrr}
\hline \multicolumn{1}{c}{ Species } & $\begin{array}{c}\text { No of data } \\
\text { for model } \\
\text { building }\end{array}$ & $\begin{array}{c}\text { No of data } \\
\text { for } \\
\text { verification }\end{array}$ & Total \\
\hline Anisoptera costata Korth. & 4 & 3 & 7 \\
Anisoptera grossinervia Slooten & 14 & 15 & 19 \\
Anisoptera laevis Ridl. & 8 & 6 & 14 \\
Anisoptera marginata Korth. & 17 & 17 & 34 \\
Anisoptera reticulata P.S.Ashton & 4 & 5 & 9 \\
Dryobalanops aromatica Gaertn.f. & 20 & 17 & 37 \\
Dryobalanops beccariana Dyer & 26 & 26 & 52 \\
Dryobalanops fusca Slooten & 19 & 19 & 38 \\
Dryobalanops lanceolata Burck & 20 & 22 & 42 \\
Dryobalanops oblongifolia Dyer & 14 & 14 & 28 \\
Dryobalanops rappa Becc. & 15 & 14 & 29 \\
Upuna borneensis Symington & 13 & 14 & 27 \\
Average & 15 & 16 & 30 \\
\hline
\end{tabular}

the other half was used for validation or accuracy assessment (Table 1) as employed by von Wehrden et al. (2009) and Jantakat et al. (2010). All data used are with 1 arc second $(c a .30 \mathrm{~m})$ resolution.

Statistical modeling especially logistic regression is often used to model the presence or absence of a species in relation to environmental or habitat variables. Environmental variables used for the binary logistic regression included bioclimatic parameters including El Nino Southern Oscillation (ENSO), topography and edaphic or soil factors. Bioclimatic data (19 parameters from 1950-2000) were downloaded from www.worldclim.org and complimented by the rainfall map (mean annual rainfall) that was generated by means of interpolation using ordinary kriging in ArcGis 9.4 as it is comparatively more accurate and representative than other interpolation methods (Nour et al. 2006; Earls 2007). The impact of ENSO was obtained from the relative average annual difference in "Normalized Difference Vegetation Index (NDVI)" between months of a severe ENSO (07/1982-06/1983) and a non-ENSO (07/ 1981-06/82) (Raes et al. 2009) and the NDVIs were downloaded from $\mathrm{ftp}$ ://ftp.glcf.umiacs.umd.edu/glcf/GIMMS/ Geographics/. Edaphic factor maps were obtained from the Harmonized World Soil Map (HWSD) from FAO/ IIASA/ISRIC/ ISSCAS/JRC (2009) while topography map were obtained from the Land and Survey Department, Sarawak. Only soil properties relevant to Sarawak were used in the study.

To avoid the problem of multi-collinearity in statistical method which will result in over-fitting of the models (Raes et al. 2009; Anon 2011), especially when numerous independent variables are generated from the same map, proxy environmental parameters were used for those environmental parameters that are highly correlated $(r>0.75)$. Based on the correlation test, only 4 soil parameters and 4 climatic parameters were therefore used in logistic regression. For soil parameters, availability of water holding capacity (proxy for subsoil texture-USDA), drainage (proxy for topsoil sand composition, topsoil clay composition, topsoil organic carbon, subsoil organic carbon, topsoil CEC, topsoil clay CEC, topsoil TEB, topsoil texture-USDA), topsoil C:N ratio (proxy for topsoil \% nitrogen content and topsoil $\mathrm{pH}$ ) and base Saturation were used. Multi-collinearilty test for the 19 climatic parameters used in this study was done by Silk et al. (2009) and therefore applied in this study as well, i.e. temperature seasonality, annual temperature range, annual rainfall and rainfall seasonality. On top of that, altitude, gradient of slope and ENSO factors were also added. The species distribution point data were overlaid with the environmental factors to obtain the various environmental data for each dipterocarp species. The data of eleven environmental parameters were then analyzed with binomial logistic regression in SPSS for possible Species Occurrence Models (SOMs) of the species. The resulted SOMs were implemented in ArcGIS for producing the Species Occurrence Probability maps for the species.

For the IDW method, the georeferenced species occurrence data were directly interpolated to construct the species occurrence map for each of the species. IDW is a method of interpolation whereby the value of the unknown point is a weighted sum of the values of $\mathrm{N}$ known points.

All the species occurrence maps resulted were reclassified into three classes using mean and standard deviation: absence ( 0 to mean -1 standard deviation) and presence (mean +1 standard deviation to 1$)$. The prediction accuracies of the models were assessed using the other half of species occurrence data. 


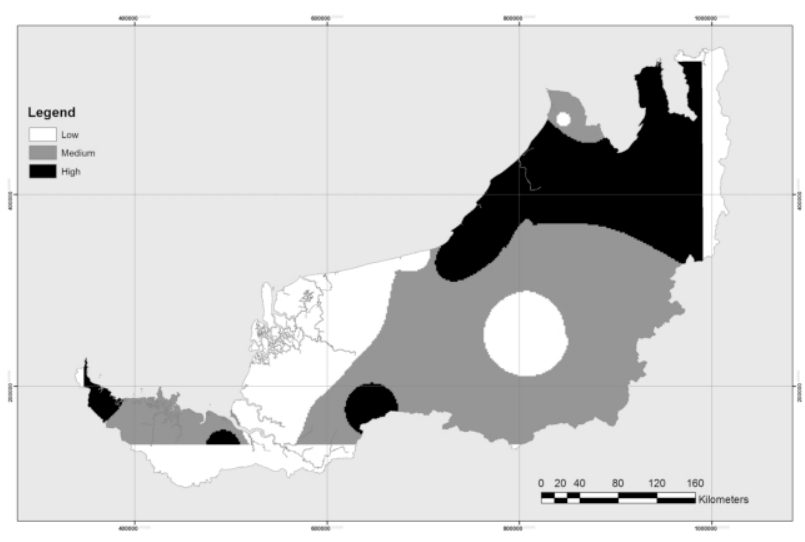

(A) Dryobalanops aromatica Gaertn. $f$.

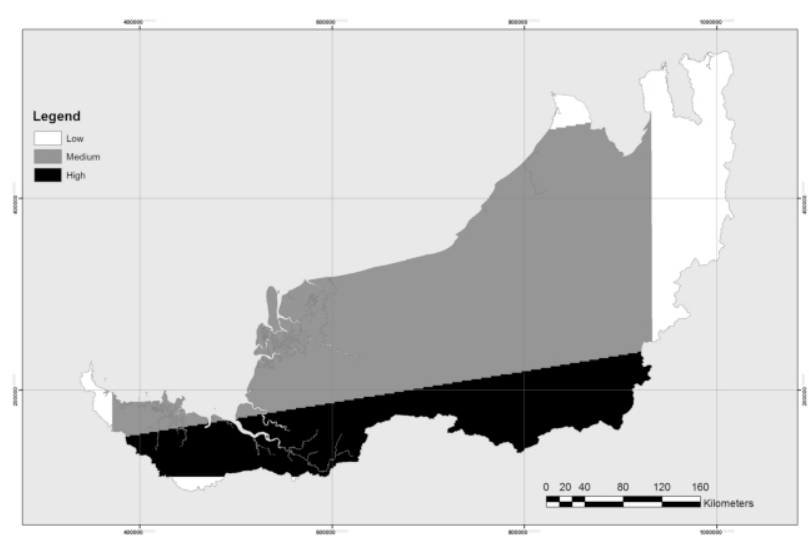

(C) Upuna boneensis Symington

\section{Results}

Firstly, the resulted SOM maps were visually examined. The SOM from IDW displayed a reasonable distributional range for each of the dipterocarp species. For instance, the peat swamp species of Dryobalanops rappa Becc. (Fig. 1B) and Anisoptera marginata Korth. (Fig. 2A) are generally found in coastal peat swamp areas and absent from the inland mountainous areas along the Sarawak-Kalimantan border. Similarly, non-peat swamp species such as Dryobalanops aromatica Gaertn.f. (Fig. 1A), were not predicted at peat swamp area, particularly in the coastal area. However, it should be noted that sometimes non-peat swamp species range can extend to the coastal areas as there are isolated hills in the coastal areas among the peat swamp. Upuna borneensis Symington, which is found mainly in the coastal areas as well as inland area of Sarawak but absent

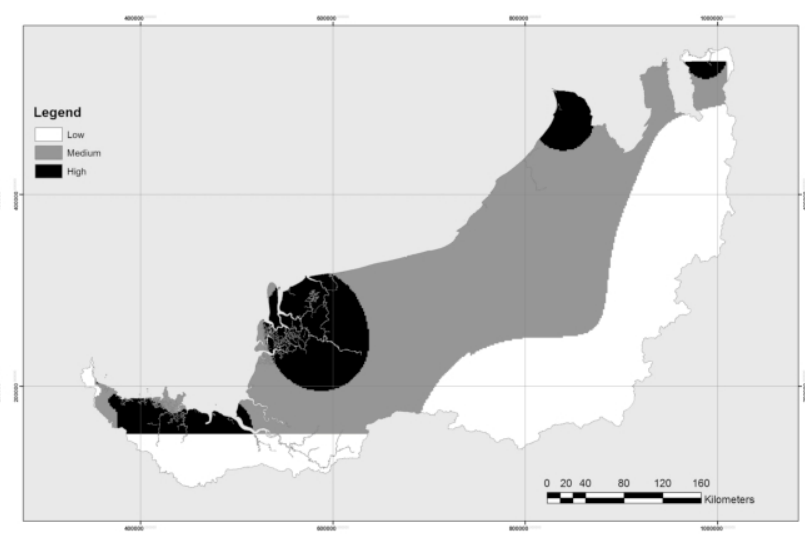

(B) Dryobalanops rappa Becc.
Fig. 1. Species distribution models or selected species for the selected genera using IDW method (A) Dryobalanops aromatica Gaertn. $f$. (B) Dryobalanops rappa Becc. (C) Upuna boneensis Symington.

from peat swamp area (Fig. 1C), are similarly correctly portrayed in the SOM. The SOMs also accurately show the distribution of species with limited geographical range, e.g. Anisoptera costata P.S.Ashton (Fig. 3).

Validation using the second set of data shows very satisfactory level of overall accuracy for all species predicted with the IDW method. The average overall accuracy was over $80 \%$ (Table 2). In contrast, the performance of logistic regression was not satisfactory. Average accuracy for Binary Logistic Regression methods was not calculated because some species had no solutions. In addition, the SOM maps from the IDW method were also more consistent (less variation in accuracy) among the species as compared with the logistic regression method (Table 2). 


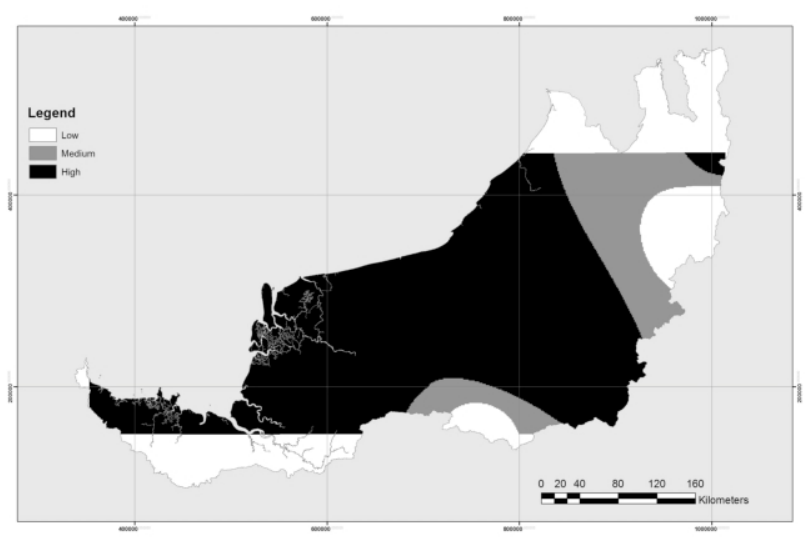

(A) IDW

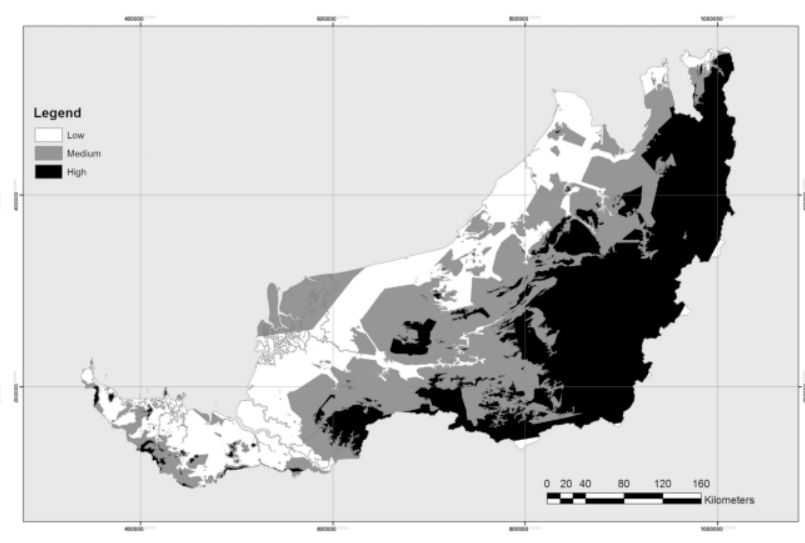

(B) Binary logistic regression

Fig. 2. Species distribution models for peat swamp species Anisoptera marginata Korth. using different modelling techniques (A) IDW (B) Binary logistic regression.

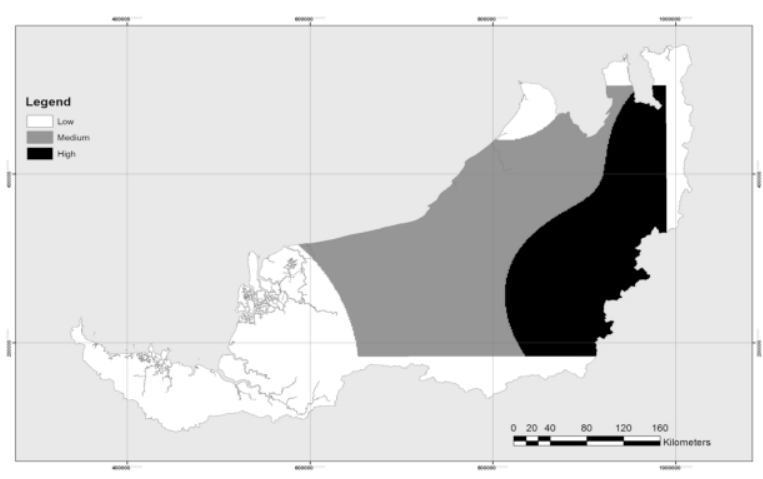

Fig. 3. Species distribution model (SOM) for Anisoptera reticulata P.S.Ashton using IDW. No solution for binary logistic regression.

\section{Discussion}

This study revealed that local interpolation method (the IDW) is better than the statistical model in terms of qualitative (visual) as well as quantitative (overall accuracy) accuracies. Binary logistic regression in this study produced inconsistent results and no solutions resulted for numerous species. The same problem was also reported by Raes et al. (2009) and von Wehrden et al. (2009). This study at landscape scale demonstrates that the dipterocarps species are not distributed randomly and that there is spatial autocorrelation.

In a study comparing logistic regression, geostatistical and maxent methods for distribution model of a forest en- demic, Sumarga (2011) found that geostatistical methods show the best prediction. Geostatistic or interpolation methods have been used for predictive mapping of trees in Europe (Anon 2012) and the United States (Hershey 2012). In the case of dipterocarps in Sarawak, the superiority of the IDW method could be attributed to the following reasons which logistic regression method does not take into account.

There are many reasons why plant population might be expected to exhibit non-randomness in distribution, making interpolation a valid procedure. Soil type, redox potentials, $\mathrm{pH}$ and so forth may be expected to strongly influence plant distribution (Crawford 1989) and hence non-randomness. Perhaps the most important of these is that plant populations including dipterocarps are not continuous variable of the type most suitable for interpolation.

Habitat-related dipterocarp species in Sarawak such as peat swamp (including the variant kerapah or peat swamp-podsolic ecotone) endemic species (eg Anisoptera marginata Korth. and Shorea uliginosa), montane endemics (eg. Dipterocarpus eurynchus Miq., Hopea montana Symington and Shorea monticola P.S.Ashton), limestone endemic (eg. Shorea calcicola P.S.Ashton) are confined to their specific habitats. Peat swamp, montane forest and limestone hills act as natural ecological confine whereby such habitat-endemic dipterocarp species are confined. This is one of the reasons why dipterocarps are not randomly distributed due to such natural ecological barriers. Besides, certain dipter- 
Table 2. Accuracy assessment for the binary logistic regression IDW methods

\begin{tabular}{|c|c|c|c|c|}
\hline & \multicolumn{2}{|c|}{ Binary logistic regression } & \multicolumn{2}{|c|}{ IDW } \\
\hline & Correct $(\%)$ & Incorrect $(\%)$ & Correct $(\%)$ & Incorrect $(\%)$ \\
\hline Anisoptera costata Korth. & 0 & 100 & 100 & 0 \\
\hline Anisoptera grossinervia Slooten & n.a. & n.a. & 80 & 20 \\
\hline Anisoptera laevis Ridl. & n.a. & n.a. & 83.3 & 16.7 \\
\hline Anisoptera marginata Korth. & 29.4 & 70.6 & 76.9 & 23.1 \\
\hline Anisoptera reticulata P.S.Ashton & n.a. & n.a. & 80 & 20 \\
\hline Dryobalanops aromatica Gaertn.f. & n.a. & n.a. & 77.8 & 22.2 \\
\hline Dryobalanops beccariana Dyer & 0 & 100 & 77.8 & 22.2 \\
\hline Dryobalanops fusca Slooten & 0 & 100 & 72.2 & 27.8 \\
\hline Dryobalanops lanceolata Burck & 0 & 100 & 80 & 20 \\
\hline Dryobalanops oblongifolia Dyer & 0 & 100 & 78.6 & 21.1 \\
\hline Dryobalanops rappa Becc. & n.a. & n.a. & 93.3 & 6.7 \\
\hline Upuna borneensis Symington & 42.8 & 57.2 & 76.9 & 23.1 \\
\hline Average & - & - & 81.4 & 19.6 \\
\hline
\end{tabular}

ocarps species are known to occupy niche habitats such as river bank or riparian forest. Among these species are Dipterocarpus oblongifolia Blume, Parashorea macrophylla Wyatt-Sm. ex P.S.Ashton, Shorea seminis (de Vriese) Slooten, Shorea macrophylla (de vriese) P.S.Ashton, Shorea splendida (de Vriese) P.S.Ashton, Shorea helmsleyana (King) King ex Foxw. and Shorea palembanica Miq. Rheophytes are plants that are restricted to the flood zone banks which are prone to flash flood, especially of swift flowing streams or rivers in the watershed region or upper course of river and are usually characterized by narrow leaves or leaf-segments with water or fish-dispersed fruits or other plant parts which are thought to be adaptations to survive in such habitat (van Steenis 1981).

Where regeneration occurs by seed a number of factors may serve to ensure plant's distribution is again not random. Many species have poor dispersal, presumably associated with reliability of suitable sites close to the parent plant (Watkinson 1978). Even when dispersal is distance, aggregation may still occur. Interruptions to air flow during wind vectoring may cause suspended seed to fall out and transport by water may similarly 'strand' floating seed where water is shallow. Faunal dispersal likewise aggregate seed. Ashton (2004) noted that dipterocarps are wind dispersed but only for short distance.

Symington (1943) observed that the distribution of Asian dipterocarps is limited by altitude because of the cli- matic environmental features and by other natural barriers such as large rivers and watersheds. Ashton (1972) noted the apparent difficulty of many dipterocarps to cross even small rivers such as the Lupar and Kemena rivers in Sarawak and explained this influence of ancient rivers upon the distribution as being the result of limited seed dispersal. However, Smits (1994) suggested that the influence of these rivers might also be related to the need of combined spread of mycobiont (specific mycorrhizae) and phytobiont (dipterocarps) and this spread would be more difficult if the choice for a suitable mycobiont would be limited because of a high degree of specificity. For instance, the distribution of Anisoptera reticulata P.S.Ashton, an endemic species of Borneo, is distributed from Sabah to the southern limit at Belaga in Central Sarawak (Fig. 3) and does not extend to the Kuching area in the south. Similarly for the genus Hopea, Hopea aequalis P.S.Ashton, Hopea altocolina, P.S.Ashton and Hopea centipeda P.S.Ashton are the three Bornean endemics that occur in Sabah in the north and extend to northern (Miri) and Central Sarawak (Bintu$\mathrm{lu} /$ Kapit) but do not extend beyond to the south or Kuching area. On the other hand, Bornean endemic species like Hopea depressinerva P.S.Ashton is only found in the south (around Kuching area). There are also similar examples in the other genera of dipterocarps. Statistical models such as binary logistic regression cannot address such distribution and would assume that they would exist on both side of the 
Batang Lupar divide.

On the basis of some indications of high degree of specificity for dipterocarp mycorrhizae, Smits (1983) developed a hypothesis about the possible role of these mycorrhizae in the evolution of dipterocarp species. This hypothesis proposes that the Dipterocarpaceae could speciate so strongly by virtue of interdependence and genetic adjustment between mycobiont and phytobiont and because of the spatial isolation resulting from the mycorrhizae relationship. According to the hypothesis concerning enhanced ecological niche specifications, dipterocarp ectomycorrhizae might be able, if not to cause, at least to strengthen qualitatively spatial isolation already induced by other factors (Smits 1994). The hypothesis concerning enhanced ecological niche adaptation by paired mutation (mycobiont and phytobiont) would present an explanation for the limited dispersal mentioned.

Spatial isolation seems to be even further enhanced, not only because of the presence of suitable mycorrhizal inoculation near the tree but also because of the existence of direct connections of one ectomycorrhizal fungus between mother tree and seedlings that benefits only the seedlings growing near the roots of the mother tree (Smits 1994). Smits (1994) did an inventory of the plot with Hopea rudiformis seedlings which indicates that there was some downhill inoculation of seedlings that germinate there whereby when further away from the root system of the mother tree the survival of those naturally inoculated plants seemed to be mainly related to the amount of light and competition. He further suggested that the result might indicate some carbohydrate transport to take place between mother tree and its seedlings (nursing role of mother trees) which he attributed to the limited distance from the mother tree at which the seedlings grow up. This myrchorrizhae relationship affects the edaphic variables as used in the statistical models.

Statistical modeling of plant species distribution is often based on the concept of equilibrium of species with their environment which resulted in biotic processes (e.g. dispersal to, and establishment in, disturbance patches) being overlooked (Dirnböck and Dullinger 2004). Disturbance, however, is an important factor structuring plant communities (Pickett and White 1985) and it affects environmental gradients (Harmon et al. 1983; Pausas and Austin 2001). It is therefore not surprising that the sole use of the environmental variables showed limited success in landscapes exposed to recurrent disturbance (Dirnböck and Dullinger, 2004).

Even if propagules are homogeneously dispersed, competition can still lead to clumped distributions in the mature plant. In salt marsh communities, for example, aggregation of competitively inferior species can be shown in the presence of competitively superior plants (Yallop 2000). And competition may be the preeminent factor in determining plant distribution in these environments (Pielou and Routledge 1976). Therefore it is reasonable to accept that plant distributions are not random and are a suitable subject for local model such as interpolation using the IDW.

\section{Conclusions}

Based on a study of three genera of dipterocarps in Sarawak, it was found that local interpolation model produces species distribution maps for dipterocarps in Sarawak with a higher predictive accuracy as well as visual assessment than statistical methods. This study demonstrated that the Inverse Distance Weighting model can be a reliable model for conservation assessment and monitoring. Species distribution maps with high accuracy that can be used for rapid assessment are important for biodiversity conservation (hotspot identification and gap analysis) and monitoring as well as assessing the impacts of environmental changes on biodiversity.

\section{Acknowledgements}

The authors wish to acknowledge supports from the Grant of Asia Pacific Network (ARCP2010-02CMYPhua) and Postgraduate Research Grant of Universiti Malaysia Sabah (GPS0016). We are thankful to Sarawak Forestry Department for support and cooperation.

\section{References}

Achard F, Eva HD, Stibig HJ, Mayaux P, Gallego J, Richards T, Malingreau JP. 2002. Determination of deforestation rates of the world's humid tropical forests. Science 297: 999-1002.

Anon. 2011. Multicollinearity in Logistic Regression. http:// www.uky.edu/ComputingCenter/SSTARS/Multicollinearityin- 
LogisticRegression.htm. Accessed on 28 July 2011.

Anon. 2012. Tree Species Distribution. European Union Joint Research Centre - Forest. (accessed on http://forest.jrc.ec. europa.eu/climate-change/species-distribution)

Ashton PS. 1972. The Quaternary geomorphological history of western Malesia and lowland forest phytogeography. In: Transactions of the second Aberdeen-Hull symposium and Malesian ecology (Ashton P, Ashton M, eds). Hull, University of Hull, pp 35-49.

Ashton PS. 1995. Biogeography and Ecology. In: Tree Flora of Sabah and Sarawak (Soepadmo E, Wong KM, eds). Sabah Forestry Department, Forest Research Institute of Malaysia and. Sarawak Forestry Department, Kuala Lumpur, pp 43-51.

Ashton PS. 2004. Dipterocarpaceae. In: Tree Flora of Sabah and Sarawak 5 (Soepadmo E, Saw LG, Chung RCK, eds). Sabah Forestry Department, Forest Research Institute of Malaysia and Sarawak Forestry Department, Kuala Lumpur, pp 63-388.

Crawford RM. 1989. Studies in Plant Survival. Blackwell, Oxford, pp 356.

Chua LSL, Suhaida M, Hamidah M, Saw LG. 2010. Malaysia Plant Red List. Peninsular Malaysian Dipterocarpaceae. Forest Research Institute of Malaysia, Kuala Lumpur. pp 136.

Dirnböck T, Dullinger S. 2004. Habitat distribution models, spatial autocorrelation, functional traits and dispersal capacity of alpine plant species. J Veg Sci 15: 77-84.

Earls J. 2007. Spatial Interpolation of Rainfall Data Using ArcGis: A Comparative Study. Proceedings of the 27th Annual ESRI International User Conference. http://proceedings.esri.com/library/userconf/proc07/papers/papers/pap_1451.pdf. Accessed on 10 June 2011.

Elith J, Leathwick JR. 2009. Species Distribution Models Across Space and Time. Ann Rev Ecol Evol Systematic 40: 677-697.

FAO/IIASA/ISRIC/ISSCAS/JRC. 2009. World Harmonised Soil Map. http://www.iiasa.ac.at/Research/LUC/External-World-soildatabase/HTML. Accessed on 26 August 2009.

Harmon ME, Bratton SP, White PS. 1983. Disturbance and vegetation response in relation to environmental gradients in the Great Smoky Mountains. Vegetation 55: 129-139.

Hershey RR, Ramirez MA, Drake DA. 2012. Using Geostatistical Techniques to Map the Distribution of Tree Species from Ground Inventory Data. http://www.fs.fed.us/ne/rsb/nant.html. Accessed on 3 July 2012.

Jantakat Y, Tessawat W, Koonto S. 2010. Forest Tree Distribution of Dry Dipterocarp Forest with Environmental Factors. Proceedings of 31st Asian Conference on Remote Sensing. Hanoi, Vietnam, pp 660-666.

Langner A, Miettinen J, Siegert F. 2007. Land cover change 2002-2005 in Borneo and the role of fire derived from MODIS imagery. Glob Chang Biol 13: 2329-2340.

Malaysian Palm Oil Board. 2009. Planted Area and Yield. 2008. http://econ.mpob.gov.my/economy/annual/stat2008/ ei_area08.htm. Accessed on 26 August 2009.
Nazeri, Mona, Jusoff, Kamaruzzaman and Madani, Nima. 2010. Habitat Models as a Research Gap in Biodiversity Conservation in Tropical Rain Forest of Southeast Asia. In: International Environmental Modelling and Software Society (iEMSs) 2010 (Swayne, David A, Yang, Wanhong, Voinov AA, Rizzoli A, Filatova $\mathrm{T}$, eds). International Congress on Environmental Modelling and Software Modelling for Environment's Sake, Fifth Biennial Meeting, Ottawa, Canada.

Nour MH, Smit DW, Gamal El-Din M. 2006. Geostatistical mapping of precipitation: implications for rain gauge network design. Water Sci Technol 53: 101-110.

Pausas JG, Austin MP. 2001. Patterns of plant species richness in relation to different environments: an appraisal. J Veg Sci 12: 153-166.

Pickett STA, White PS. 1985. The ecology of natural disturbance and patch dynamics. Academic Press, San Diego, CA.

Pielou EC, Routledge RD. 1976. Salt marsh vegetation: Latitudinal gradients in the zonation patterns. Oecologia 24: 311-321.

Raes N, Roos MC, Slik JWF, van Loon EE, ter Steege H. 2009. Botanical richness and endemicity patterns of Borneo derived from species distribution models. Ecography 32: 180-192.

Roos MC, Kessler PJA, Gradstein SR, Baas P. 2004. Species diversity and endemism of five major Malesian islands: diversity-area relationships. Journal of Biogeography 31: 1893-1908.

Slik JWF, Raes N, Aiba SI, Brearley FQ, Cannon CH, Meijaard E, Nagamasu H, Nilus R, Paoli G, Poulsen AD, Sheil D, Suzuki E, van Valkenburg JLCH, Webb CO, Wilkie P, Wulffraat S. 2009. Environmental correlates for tropical tree diversity and distribution patterns in Borneo. Diversity and Distributions 15: 523-532.

Smits WTM. 1983. Dipterocarps and mycorrhiza: an ecological adaptation and a factor in forest regeneration. Flora Malesiana Bull 36: 3926-3937.

Smits WTM. 1994. Dipterocarpaceae: Mycorrhizae and regeneration. Tropenbos Foundation, Wageningen.

Sumarga E. 2011. A comparison of logistic regression, geostatistics and maxent for distribution modeling of a forest endemic: a pilot study on lobels maple at MT Pizzalto, Italy. Masters Thesis. Twente University, The Netherlands.

Symington CF. 1943. Foresters Manual on Dipterocarps. Malaysian Forest Record 16, Forestry Department of Peninsular Malaysia, Kuala Lumpur.

Tsuyuki S, Goh MH, Teo SP, Kamlun KU, Phua MH. 2011. Monitoring deforestation in Sarawak, Malaysia using multitemporal Landsat data. Kanto Forest Research 62: 87-90.

van Steenis CGGJ. 1981. Rheophytes of the World. An Account of the Flood-Resistant Flowering Plants and Ferns and the Theory of Autonomous Evolution.-With 23 photographs, 44 figs., 408 pp.-Alphen aan den Rijn, The Netherlands/Rockville, Maryland, USA: Sijthoff \& Noordhoff.

von Wehrden H, Zimmermann H, Hanspach J, Ronnenberg K, Wesche K. 2009. Predictive mapping of plant species and com- 
munities by using GIS and Landsat data in a southern Mongolian mountain range. Folia Geobotanica 44: 211-225.

Watkinson AR. 1978. The demography of a sand dune annual: Vulpia fasciculata JII. The dispersal of seeds. J Ecol 66:
483-498.

Yallop A. 2000. Biotic interactions in salt marsh communities with special reference to arbuscular mychorrhial fungi. $\mathrm{PhD}$ thesis. University of East Anglia, UK. 